\title{
Research on the English Translation of Promotional Texts of Sichuan Intangible Cultural Heritage from the Perspective of Memetics
}

\author{
Li Xiao \\ School of Foreign Languages, Southwest Medical University, Luzhou Sichuan, China \\ E-mail: xiaoli60711@163.com
}

Keywords: English Translation, Promotional Texts, Sichuan Intangible Cultural Heritage, Memetics

\begin{abstract}
There is an incompatibility between the textual introduction and translation of the intangible cultural heritage, but it cannot be simply classified as the quality of translation. Based on Baker's theory of narratology framework, this study analyzes the narrative framework of the source text and the translation of intangible cultural heritage products, the translation strategies and the values, thinking systems and discourse powers involved in the framework, points out the official mainstream discourse, the value orientation of the translator and his agency and the translator's position and intention affect the establishment and reconstruction of the non-heritage narrative framework. As a result, the translation and the source text also form a space for mutual interpretation, objectively promoting non-epic texts accept and disseminate.Then,this essay analyzes the English translation of promotional texts of Sichuan Intangible Cultural Heritage from the perspective of memetics.
\end{abstract}

\section{Introduction}

In today's diverse era, culture is the most embodyive element of self-worth, especially the precious cultural heritage that survived the test of time and history. These heritages are an important part of a country's "soft power." Non-heritage coincides with the "going global" cultural strategy advocated by our country so far. The study and translation of non-heritage books cannot only protect and enhance its own development, but also promote exchanges among all ethnic groups and the protection and promotion of cultural diversity Has extraordinary significance. Chinese non-heritage often has strong national and local characteristics. Only by building a bridge of mutual communication through translation can Chinese profound culture be understood by the people of the world. However, non-legacy translation is not easy: two distinct languages, two very different cultures, what are the difficulties in translation, and how should non-translators handle it?

\section{The Strategy Perspective and Frame Presentation of Non-Translated Text}

Baker included the factors of conflict, resistance and subversion in translation studies, examining translation from the context of tension, and pointed out that the essence of translation is a kind of narration. According to Baker's argument, the narrative framework of the original text and the re-narrative framework of the translation may be the same, there may be big differences. For translating the same text, the translator can translate it into different narrative texts that are completely contrary to each other based on different narrative frameworks. However, when the source texts (such as the Chinese profile of non-heritage articles) are presented in different narrative frameworks the corresponding or related English text will certainly be different. In view of the translation of Liangzhu's legend, this study investigated sources such as "Sichuan intangible cultural heritage", Chinese Culture Network, Fudan University's Confucius Institute Website, Chinese Language Network for Overseas Learning, Sichuan Tourism Bureau Website, China Daily English 
Network and other sources. Only Fudan The Confucius Institute Online website and the Chinese Learning Network for Chinese as a Foreign Language (SOP) strictly control non-Retribution posters by paragraph by paragraph, while other related books or websites have different narrative frameworks. For example, the Legend of Liangzhu of China Daily English website, in accordance with the format of non-widow newspaper, in turn, indicate the time, type, area and number, but lack of reporting units; the content brief introduction is also different from the Chinese text, Only the last three paragraphs were translated based on the Chinese version of the non-widow notation:

First, opera and folk art series. The most famous Sichuan Opera, which is a wonderful flower in Chinese opera hundred gardens, renowned at home and abroad. In addition, Sichuan Qingyin, dulcimer, bamboo Qin, northern Sichuan lantern, Nanchong puppet, Wang Wenkun shadow play, Lushan light play, Guang'an basket play (palm puppet show), Sichuan money board, lotus leaf, Nine lotus lights, Guangyuan archery Yang play and Nanchong Chuanxu opera, Lushan Qing altar, and so on.

Second, Wenchang culture and moral culture. Zitong Qi Temple is the hometown of Wenchang Dijun, Wenchang culture and the derivative of Dongjing music; Deyang Xiaoquan town is the birthplace of Jiang poetry and morality culture; Meishan City, Pope's longevity culture and the hometown of Li Mi's filial piety culture has unique characteristics.

Third, national folk music and dance, important are: Kangding love songs (with the world influence), Chuanjiang, Tuojiang and Jinshajiang son, Qiang's Castanet (armor) dance, Sharon dance, sheepskin Inspired by the White Horse possession of the twelve phase (Hundreds of beasts dance), Songpan Disa, Bashan back brother, Benjamin Qiang, Ruoergai begging "golden crown dance", the Qiang Songbi epic rap, Bangtangxianzi, Pakistan and Nanchong The Bayu dance and Pakistan as drums, North Sichuan hay grass percussion, Tibetan and Qiang multi-part folk songs, Panzhihua Si Sha Sa Village Pu Pu ancient music, and so on, brilliant.

Fourth, folk oral literature series. There are abundant folk oral literature resources in all parts of Sichuan. The most distinctive is the epic epic of King Gesar's biography of Aba and Ganzi. Garze is the hometown of King Gesar, whose epic rap has the characteristics of Kham.

Fifth, folk art and crafts. Important are: Mianzhong version of New Year paintings, Aba's black tents and Tibetan boots, Beichuan and other places of Qiang embroidery process, white masks Tibetan masks, Mongolian Thangka, Aba's arm Suva Bridge process, Taoping The Qiangzhai dwelling house, the Wenchuan Bohai loess tower, the Suining Yingzhuo Zhuangkuai craft, the Guang'an bamboo silk curtain, the Qingzhu bamboo, the Zigong Gong fan and the tie dye, Chengdu sugar painting, Shujin, Shu embroidery, lacquer art, Luzhou Laojiao Brewing skills, sand technology, Zigong deep well salt drilling technology, Deger Printing Institute Tibetan engraving printing skills.

\section{The Construction Space and Translator's Intent of Non-Translated Frame}

The non-ephemeral texts) published online in Sichuan intangible cultural heritage are authoritative and acceptable. However, the relevant English versions adopt the "alternative diversion of text material" strategies through compression, deletion and reorganization, Constructed a new narrative framework. In response to such phenomena, Beck put forward the concept of "constructing space". She pointed out that in all interactions (including translation), different actors play different roles, participate in interactions in different capacities, and hold different positions on current events and other participants. All of these possibilities the superposition, constitutes the so-called construction space (Baker, 109). The construction of space has certain rules, which may be clearly written or invisible, but in any case, the translator's behavior will be "limited by the construction space", and the translator "scrutinizes" from the construction space their language behavior, "while building the space also" defines the boundaries of the translator's discourse media "(Baker, 110). However, the translator can also take a variety of ways to weaken the construction space, so as to realize the reconstruction of the narrative. Sichuan is a colorful and rich intangible cultural heritage resource. It is the root of Bashu's life memory and the root of Bashu culture. It is also an important part of "Chinese memory." Compared with the material and cultural heritage, it is 
more dynamic rhetoric, ecstasy characteristics. It embodies the unique spiritual world and spiritual activities of Bashu people, and concentrates on the romantic and unique dreamlike features of Bashu people. From the strangeness of the Sanxingdui and Gansha ancient Shu people to the free ride of Sima Xiangru's Da Fu; From the wittyness of the ancestor of the rap art - the rap figurines unearthed in the Chengdu Plain of Eastern Han Dynasty to the unrestrained imagination of Li Bai; Immortalized thinking, to Guo Moruo pan-romance and romance; from the change of Sichuan Opera, to the harmony of multi-ethnic song and dance, all show Sichuan people magical, mysterious, wonderful, colorful spiritual world, which is the most abundant in the world, The most delicate and the most extraordinary areas. Therefore, Du Fu praised the people here as "new people," and the civilization here is "incompatible with the letter and beauty." It shows all aspects of Sichuan's ethnic groups, folk customs and folk customs. It has become the fountainhead of the Sichuan people's soul and the inner driving force of the spiritual creation and the spiritual home of harmony in Sichuan. This is Sichuan's most cherished heritage, need to fully protect and heritage.

\section{The Translation Principles of Non-Nonessential}

The United Nations requests that the information materials submitted by non-descendant applicants contain two parts, namely, "Description" and "Nomination Form" (in tabular form) filled out by non-reserved applicants. The items to be filled in are: Name of Party, Name of NonIncluding definitions, contribution to the promotion of cultural dialogue, etc.), and clearly state in the written description that "the best objective language" be completed. Clearly, non-ephemeral texts, grouped according to Katharina Reiss's typology of texts, should be classified as "informative texts that objectively state 'information, knowledge, opinions' Using Logical or Indicative Language, "the linguistic function is to provide the reader with information that should be" plain and simple, without redundancy, and to clarify the translation if needed "(citing Munday 2001: 73-4) . Here we excerpt a section of English material selected in "China Abacus" of the "World Unrequeased Catalog" in 2013 to see how it reflects the language requirements of informational translations.

The translation uses three commonly used sentences in English (with structure, past participles adverbial two simple sentences, while leading composite sentence), using objective, logical language to us to convey the Chinese abacus such a few Information: Core Concepts (Knowledge and Practice), Tools (Abacus), Competencies (Algorithms), Material (Bamboo or Wood), shape (Rectangle), Basic Frame ( 1 bead on the beam, 4 beads on the beam) or 7 beads ( 2 beads on the beam, 5 beads on the beam), the value (1 bead on the beam is 5 and 1 bead on the beam is 1) in parentheses, however, it has been clarified, but there is no sense of redundancy. On the contrary, it highlights the characteristic of the complete transmission of information texts (concept content here). After reading the Western readership, Abacus will have a clear concept of physical cognition.

The reason why the principle of concision is raised is that firstly the translation produced by the annotation method may lead to complexity and cumbersomeness because of its exhaustiveness, thereby reducing the readability of the text and disqualifying the assessors from reading. At this time, the translator should not over-comment, but simply use simple language to make it simple and concise. The author found in the process of finding information, there are many translation of the interpretation of the problem there is extra, here only take the Chinese culture network on the "Pipa" translation as an example: "Pipa, four-stringed lute with 30 frets and pear-shapedbody" However, referring to the Oxford Dictionary, the "lute" in the West is itself a pear-shaped body, and some information is redundant after the translation. Second, the Operating Guidelines set strict limits on the number of words to be filled in each. Even audio and video materials, including submissions have time limits and are not subject to approval or assessment for exceeding the word limit or time limit. This objectively requires succinctness as a principle of non-English translation. The translator should be able to condense each item's name, basic introduction, protection measures and other items on a clear and complete basis. 


\section{Conclusion}

It is the cultural memory and cultural existence of the Chinese nation that is deeply rooted in the local culture. The concept of non-heritage culture is also the essence of the nationality and heterogeneity of Chinese culture. However, how to preserve cultural heterogeneity has become a non-cultural heritage A Primary Consideration in the Process of Conceptual Translation. In this regard, the study proposed five methods under the guidance of alienation strategy. Of course, we do not rule out the use of paraphrasing for syntactic or discourse reasons. This study only refers to the cultural concept of non-occidental ethnics. Using these methods is consistent with the original intention of the UN Convention and is conducive to national culture identity maintenance. As the non-legacy application continues to heat up, the non-heritage Chinese translation study will also usher in a climax. It is hoped that the methods and principles proposed in this study will attract more scholars and attract more scholars to pay attention to non-English translations, boosting provincial and municipal levels from the perspective of translation, non-legacy national non-heritage to world-class non-heritage and colorful Chinese culture shine in the world culture kaleidoscope.

\section{Acknowledgements}

Fund Project: Sichuan Provincial Department of Education base project - Sichuan Tourism Development Research Center, Project Number: LYC16-37

\section{References}

[1] Chen Fangrong. Cultural diversity and intangible cultural heritage translation [J]. Journal of Zhejiang Normal University (Social Science Edition). 2013 (03)

[2] Hu Qinghong, Wen Jun. Translation of Sichuan intangible cultural heritage from the Perspective of Communication [J]. Shanghai Translation. 2016 (02)

[3] Yan Jie, Li Xiaoli. 2004-2003 Chinese medicine translation of the bibliometric analysis [J]. Chinese Journal of Basic Medicine. 2016 (04)

[4] Hu Weihua, Li Ying. "Alienation" "naturalization" under the perspective of the Chinese market luxury brand translation [J]. Journal of Xi'an International Studies University. 2016 (02)

[5] [J]. Journal of Xi'an International Studies University. 2016 (02)

[6] Jiang Jibiao, Zhang Jianbin. Metaphor from the perspective of acupoints named English translation study [J]. Chinese Journal of Basic Medicine of Traditional Chinese Medicine. 2015 (03) 